\title{
Somali Torture Survivors in Canada
}

\author{
Joan Simalchik
}

Frequently, it is the presence of refugees in a host community that alerts a wider audience to a particular situation of human rights abuse. Such is the case of Somalia. From the mid-1980s to today, Canadian immigration reports that thousands of Somalis have sought refuge in Canada. Large numbers of these refugees who fled from the Siad Barre regime testified to experiences of violent persecution, mass repression and torture.

Somali torture survivors approached the Canadian Centre for Victims of Torture (CCVT) for assessment, documentation, counselling and treatment. Successive CCVT annual reports record the numbers of Somali survivors seeking help. In 1987 the Centre registered thirtysix Somali cases; in 1988, twenty-two cases; in 1989, ninety-two cases; in 1990, 121 cases; and in 1988, 272 new intakes were conducted. Three hundred women were on the waiting list for the Centre's mutual support group.

By 1990, Somali refugees were increasingly making their presence known throughout Canada. Community members formed a variety of organizations and began to join the staffs of settlement and social service agencies, as well as mainstream institutions, universities and colleges. Still, despite the contributions being made, Somali refugees had the trauma of their past experiences to surmount in addition to the obstacles of settlement.

CCVT doctors soon recognized the legacy of trauma as manifested in Somali torture survivors. Writing in the National Academy of Science's 1988 report, Scientists and Human Rights in Somalia, Dr. Wendell Block stated: "The incidents described to me spanned the period between August of 1977 and August of 1986. Most of these men continued to complain of a variety of

Joan Simalchik is associated with the Canadian Centre for Victims of Torture, Toronto somatic and psychological problems, typical of torture victims. Somatically, these included spells of dizziness, headaches, stomach pains, back pains, aching eyes, knee pains, coughing and choking feelings. Psychologically, there were frequent complaints of nightmares, poor sleep, poor appetite, difficulties with short-term memory and concentration, fatigue, depression and anxiety." He continued, "The most common visible, physical scars were those of abrasions and lacerations, entirely consistent with whippings, kicks, bayonet cuts and other methods of beatings described. They were located on faces, chests, backs, abdomens, arms, legs and feet."

Dr. Donald Payne, a psychiatrist in private practice and coordinator of CCVT's Medical Network, wrote: "It had severe scarring on his arms, legs and back. His scars were strongly suggestive of injury with a sharp object occurring in a similar fashion to different areas of his body. In over ten years of examiningover 200 torture victims, I have never observed such dramatic signs of previous injury."

The internal political situation in Somalia has deteriorated and is now worsened by a severe drought. Somali refugees in Canada experience severe difficulties. Many are separated from families, others face uncertain immigration decisions and still others struggle to recover from incidents of torture, imprisonment and persecution. The impact of losing one's country, family and pastlifeis greatly exacerbated by memories of intense personal violation and maltreatment. Specialized

\section{Specialized service is necessary, but recognition and support from the larger community remains vital for those who have endured and survived the torment of torture.}

appears that little effortwasmadeto hide the fact that the victims had been tortured. They were punched, kicked and hit with sticks, whips and rifles. Almost all the individuals reported threats to their lives and found this quite terrifying as it appeared that their death could result from a whim of the guards rather than requiring any order from a higher authority."

Dr. Philip Berger wrote of a thirteenyear-old boy who was detained. He was "repeatedly stabbed with bayonets to his chest, back and buttocks. He says he was hung by his leg from a tree, kicked and slapped and burned with cigarettes to his face. He exhibited severe and extensive scarring with over fifty scars counted over all parts of his body. Most notable were five identically shaped scars on his chest. These were in forms of crosses with each line of the cross ranging from five to seven $\mathrm{cm}$ and thickened. He service is necessary, but recognition and support from the larger community remains vital for those who have endured and survived the torment of torture.

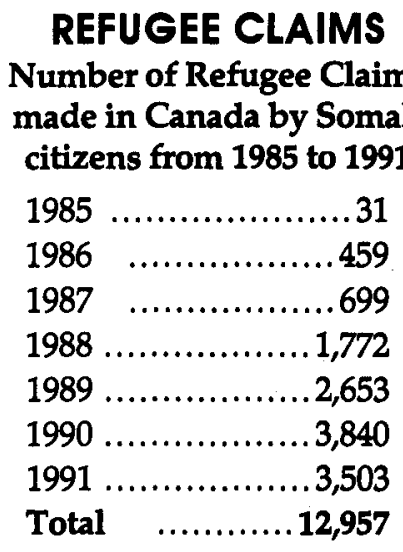

Source: CEIC/IRB 